See discussions, stats, and author profiles for this publication at: https://www.researchgate.net/publication/308967930

\title{
The Conflicting Path of Ethnic Diversity: Protesting Minorities in Europe
}

Article $\cdot$ January 2010

DOI: 10.1163/22116117-90001633

\section{CITATIONS}

0

1 author:

\section{Victor Cebotari}

University of Luxembourg

34 PUBLICATIONS 162 CITATIONS

SEE PROFILE

Some of the authors of this publication are also working on these related projects:

International migration, gender and the educational development of children in Tajikistan View project

TCRAF-Eu View project

\section{READS}

20 


\section{The Conflicting Path of Ethnic Diversity: Protesting Minorities in Europe}

\section{INTRODUCTION}

Perhaps the most prominent issues of interest in social studies of the recent decades have been ethnicity and ethnic conflict. Generally, ethnic conflict poses a substantial risk to national stability worldwide, and Europe is not immune to this threat. With the relatively recent end of the cold war era, there was a domino effect of regime transitions of many if not all of the former European communist countries. Following this ideological change, many scholars have predicted that democratization, conflict and ethnicity will become an important focus of international politics. Various scenarios evolved of how ethnic conflict will be shaped: from "the clash of civilizations" to the "continuing unending nature of conflicts."

In such context, ethnopolitical protest is commonly believed to peacefully accommodate the challenging demands of ethnic diversity. The collapse of communism and the formation of the new democratic regimes in Europe opened a wide range of opportunities for ethnopolitical movements to manifest. According to Tedd Gurr, the peak in ethnic mobilization was achieved at the beginning of the 1990s, after which ethnic challenges continuously dropped. ${ }^{3}$ Moreover, a general shift can be observed in ethnopolitical activism, from violent rebellion to peaceful protest, which mainly converged with the increasing democratic governance in the 1990s. ${ }^{4}$ Scholars further believe that the change towards peaceful mobilization is due to an increasing attention towards

\footnotetext{
* Victor Cebotari is a Marie Curie PhD Fellow at Maastricht Graduate School of Governance, Maastricht University.

1 Samuel Huntington, The Clash of Civilizations and the Remaking of World Order (Simon and Shuster, New York, 1996).

2 Richard Haas, Conflicts Unending: The United States and Regional Disputes (Yale University Press, New Haven, CN, 1991).

3 Tedd R. Gurr, Peoples Versus States: Minorities at Risk in the New Century (USIP Press, Washington DC, 2000), at xvi.

$4 \quad$ Ibid., xiii
}

European Yearbook of Minority Issues Vol 7, 2007/8, ISBN 9789004 I7990 5, I8I-207.

(C) 2010 Koninklijke Brill NV. Printed in The Netherlands. 
strategies of recognition and integration of ethnic minorities..$^{5}$ Especially in Europe, these strategies have a longstanding value and have reached the point where the borders between assimilation and integration have almost disappeared. ${ }^{6}$

Increasing attention should be therefore given to protesting actions, as being an important choice among ethnic groups to actively mobilize in Europe. I build on previous theoretical work that employs perennialist, ${ }^{7}$ primordialist $^{8}$ and constructivist ${ }^{9}$ ideas to consider those factual conditions under which ethnopolitical protest is more prone to manifest. Many engagements in protest or any other form of communal conflict result from an "ethnic security dilemma"-a concept and strategy reflecting the realist tradition of intergroup relations. ${ }^{\text {Io }}$ Barry Posen would argue that "the condition of anarchy makes security the first concern of states" ${ }^{\text {II }}$ and consequently, ethnic communities behave in the same manner as sovereign states in the international system. When two or more ethnic groups coalesce, each of the actors tries to maximize its own security in relation to its neighbouring communities. Any action taken by a communal group, however, automatically triggers reactions from the opposing group, which sees it as an affront to their own ethnic security. It could be a never-ending process empow-

5 Ibid., xiv.

6 Tariq Modood, “Remaking Multiculturalism after 7/7”, Open Democracy, 29 September 2005, at 2, at <http://www.openDemocracy.net>, accessed 20 September 2008.

7 Perrennialism explains ethnic mobilization from the perspective of the group ethnic continuity shaped by a set of values and beliefs. For more-concise information regarding this debate see Huntington, op.cit. note 1; Anthony D. Smith, The Ethnic Origin of Nations (Basil Blackwell, Oxford, 1986); Anthony D. Smith, Myths and Memories of the Nation (Oxford University Press, Oxford, New York, 1999), at 5-27.

8 Primordialism sees ethnic mobilization through the lens of groups' primal features and their historical heritages. The primordial objects such as biological characteristics, religion, language and territory are powerful factors productive of conflict. The primordialist incentives of conflict were treated in, among others, Donald Horowitz, Ethnic Groups in Conflict (University of California Press, Berkeley and Los Angeles, 2000), at 57; Donald Horowitz, "The Primordialists", in Daniele Conversi (ed.), Ethnonationalism in the Contemporary World: Walker Connor and the Study of Nationalism (Routledge, London, New York, 2004), at 72-73; Steven Grosby, "The Verdict of History: The Inexpugnable Tie of Primordiality-A Response to Eller and Coughlan”, 17(1) Ethnic and Racial Studies (1994), 164-171, at 168 .

9 Constructivists consider mobilization as deriving from social and political practices, in which a set of social instruments bust the intensity and direction of ethnic movements. See also Benedict Anderson, Imagined Communities: Reflections on the Origins and Spread of Nationalism (Verso, London, 1991), at 16; Daniel Posner, "The Implications of Constructivism for Studying the Relationship between Ethnic Diversity and Economic Growth", paper presented at the Annual Meeting of the American Political Science Association, Hilton Chicago and the Palmer House Hilton, Chicago, IL, 1-5 September 2004.

10 For a critical view on this issue see, Horowitz, op.cit. note 8, 95.

11 Barry R. Posen, "The Security Dilemma and Ethnic Conflict", in Michael Brown (eds.), Ethnic Conflict and International Security (Princeton University Press, Princeton, NJ, 1993), 104. 
ered by the idea that "what one does to enhance one's own security causes reactions that, in the end, can make one less secure." ${ }^{2}$

Keeping in mind all these factual conditions, I explicitly set the goal of empirically observing the particularities of ethnic-group mobilization defined as ethnocommunal protest. Supposing that the general ratio of protest movements diminished per se in the past two decades, would the intensity of protest decrease as well? And if there are changes in protest intensity, what is the magnitude of the transition rates over time? Moreover, considering that there are significant changes in protest actions over time, does the previous status in protest influence the current protest mobilization? There are no consistent studies, especially in Europe, that might explain whether the decreasing trend in ethnic strife is caused by a process towards a permanent choice for "no mobilization" or is just caused by a relative and temporal decline in strife intensity among ethnic groups. Apart from looking at the changes in protest intensity across time, the question of which causal factors shape the consistency of ethnic mobilization will be addressed as well. In doing so, I attempt to observe the link between some group- and country-level conditions (such as democracy, discrimination, regional concentration ethnic fractionalization, etc.) and the growing strength of communal mobilization.

First, I will explain what ethnicity and ethnic group means in the context of this analysis. Second, I will define some of the key terms used in this study. Third, I will underline what indicators this study employed and what expectations can be predicted based on previous scholarly work. Fourth, data characteristics, methodology and operationalization of variables will be explored. Fifth, in line with the established questions, the empirical results will be presented. Finally, my concluding remarks will summarize the content of this analysis.

\section{Defining Key Terms: Ethnicity and Ethnic Mobilization}

\section{A. Defining Ethnicity}

Ethnicity, as an analytical concept, emerged in the early 1960s, being widely theorized in social science. Precisely defining an ethnic group however poses more challenges than one might expect. There is by far no consensus on this concept, and any definition from the literature is not by itself totally representative of a certain country or region. This defining pattern is even more challenging when it comes to targeting ethnic groups in Europe. Some European ethnicities can identify themselves with only one significant cultural difference, such as religion (e.g., Bosnian Serbs and Muslim, or Catholics in Northern Ireland). Others build their ethnic distinctiveness on language or cultural and racial heritages (e.g., the Basques in Spain and France, Slavs in Moldova, Hungarians in Romania). Therefore, a standard definition of an 'ethnic group' based merely on general and shared cultural features is somehow deeply problematic. ${ }^{\text {33 }}$

12 Ibid., 104.

13 James Fearon and David Laitin, "Ordinary Language and External Validity", paper presented at the Annual Meetings of the American Political Science Association, September 2000, Washington, DC, 12. 
I tend nonetheless to rely on the idea that the concept of ethnicity is mainly marked by the fact that an ethnic group is a distinct entity, shaped by a collective identity and, more important, by the recognition of others of its basic primordial conditions. Starting from these ideas, I identified two general definitions in the literature that come closer to my perception of an ethnic entity. The first one sees ethnic groups as cultural communities based on a common belief in a real or putative descent. ${ }^{\mathrm{I}}$ The second one follows Anthony Smith's definition of what he calls an "ethnic community": "a named human population with a myth of common ancestry, shared memories, and cultural elements; a link with a historic territory or homeland; and a measure of solidarity." ${ }^{15}$ A common feature of these definitions is to consider all ethnic groups as distinct perennialist, constructivist, but especially primordialist entities with a set of different cultural values and identities that distinguish them from the majority group(s) in a country. States which have control over these ethnic minorities can be conceptualized as dominant units that maintain their domination by coercion. ${ }^{16}$ Many minority groups choose a dynamic mobilization process in relation to the dominant majorities, at the communal but also at the national level, that is situational and very much prone to change in time. ${ }^{17}$ Consequently, ethnic activism should be seen as a result of these dynamic processes in which distinct ethnic communities would continuously want to reinforce their ethnic distinctiveness in opposition to their neighbouring group. I thus consider the idea of the ethnic security dilemma as being endemically embedded in a multiethnic society.

Even though there are a multitude of groups prone to be mobilized, ${ }^{18} \mathrm{I}$ primarily focus on those ethnic minorities that are mostly at risk to be discriminated either in relation to the dominant group in the country or by the central ruling authority in the state. The criteria "at risk" to which certain groups are considered discriminated have been empirically established by Ted Gurr in the Minorities at Risk (MAR) project and are explicitly posted in the "Data" section below.

14 Max Weber, From Max Weber: Essays in Sociology (Oxford University Press, New York, 1946); cf. Lars-Erik Cederman and Luc Girardi, "Beyond Fractionalization: Mapping Ethnicity onto Nationalist Insurgencies. Dissagregating the Study of Civil War and Transnational Violence", paper presented at University of California Institute of Global Conflict and Cooperation, 27 February 2005, San Diego, CA, USA, 4; cf. Anthony Smith, National Identity (University of Nevada Press, Reno, 1991), 21.

15 Anthony Smith, Nations and Nationalism in a Global Era (Blackwell Publishers, Malden, MA, 1995), 56-57.

16 Ibid. See also John F. Stack, The Primordial Challenge: Ethnicity in the Contemporary World (Greenwood Press, New York, 1986), 1-5.

17 Tedd R. Gurr, Minorities at Risk: A Global View of Ethnopolitical Conflicts (United States Institute of Peace Press, Washington, DC, 1993), 162.

18 See Horowitz, op.cit. note 8, in which he distinguishes between the advanced and backward groups and their patterns in mobilization behavior. 


\section{B. Defining Ethnic Mobilization}

In contemporary intra-state politics, ethnic mobilization can take various forms. One can see mobilization as a range of events going from peaceful sporadic or sustained protest to more-violent confrontations, civil war or insurrections. Others, conversely, consider ethnic conflict an engagement in the political process. A group that is politically active has become mobilized, but it does not automatically mean that they will seek to protest or rebel. In both these scenarios, nevertheless, ethnicity has a significant role. Based on ethnic feelings or the group's status of discrimination, conflict may ignite between two or more different national communities or between an ethnic group and the state ruling authority.

Much literature focuses on ethnic movements in terms of their extreme outcomes that are based on violent rebellion. Monica Toft considers that ethnic mobilization is strongly associated with the idea of sovereignty over a specific territory and thus ethnic disputes are often associated with violence. ${ }^{19}$ Donald Horowitz also assumes that ethnic conflict is in general more violent than are ideological or political mobilizations. ${ }^{20}$ His opinion reflects the idea that ethnic conflicts are more emotional and thus more intense.

As previously mentioned however, there is empirical evidence of a shift in ethnic action, from violent conflict toward protest. ${ }^{2 \mathrm{II}}$ In his recent studies, Jonathan Fox concluded that few of the ethnic conflicts in the democratic world have characteristics other than low-intensity conflict. ${ }^{22}$ European ethnic minorities are especially open to non-violent conflicts because of several well-tested reasons in the academic literature. Peaceful characteristics of protest make it more prone to grab the attention of the decision-making authority. Similarly, ethnic groups will push less for collective violence as far as they are confident that their demands have a higher chance to be fulfilled through peaceful methods. ${ }^{23}$

There are a series of characteristics that can be linked to protest mobilization. Olzak and Tsutsui ${ }^{24}$ consider ethnopolitical protest a particularity of ethnic mobilization that is characterized by a racial or ethnic grievance directed at the government officials (state authority) or towards the community at large. There are two main features of protest movements that according to Lewis Killian represent the fundament of each mobilization: actions to promote or resist change and the mobilization resulting from the collective behaviour. ${ }^{25}$ In the course of this analysis, ethnopolitical protest

19 Monica D. Toft, The Geography of Ethnic Violence: Identity, Interests, and the Indivisibility of Territory (Princeton University Press, Princeton, NJ, 2003).

20 Horowitz, op.cit. note 8.

21 Gurr, op.cit. note 3, xvi.

22 Jonathan Fox, "Trends in Low Intensity Ethnic Conflict in Democratic States in the PostCold War Era: A Large N Study", 2(3) Review of International Affairs (2003), 54-70.

23 Ibid. See also Gurr, op.cit. note 3.

24 Susana Olzak and Kiyoteru Tsutsui, "Status in the World System and Ethnic Mobilization”, 42(6) JCR (1998), 691-720, at 694.

25 Lewis M. Killian, "Social Movements", in Robert E. Faris (ed.), Handbook of Modern Sociology, (Rand McNally, Chicago, 1964), 426-455, at 430. 
includes activities by the members of an ethnic group or on behalf of an ethnic minority directed against the state authority and explicitly organized to defend minority rights and interests. As a general characteristic, it excludes any threat or use of violent coercion.

\section{Indicators AND Expectations}

While defining ethnic mobilization, this study focuses on ethnopolitical protest as its dependent indicator. MAR records information on protest actions by ethnic groups directed against the majority or the dominant group(s) who might also represent the ruling authority in the state. The base of the ethnopolitical protest is to assert and protect the general group interests. ${ }^{26}$ In doing so, the protesting actions may vary in range and intensity from verbal opposition and symbolic resistance to large-scale demonstrations.

A handful of control variables are also included in the analysis. They represent the causal linkage to the explanatory side of the empirical model. These indicators are listed below.

\section{A. Political Discrimination}

Any form of discrimination is logically linked to an increased desire for mobilization. The presence of political discrimination against an ethnic community leads to dissatisfaction and grievance formation, which are likely to be transformed into a chain of mobilization events. Previous empirical studies have shown that ethnic groups are more likely to rebel when their political status is threatened by the ruling authority. ${ }^{27}$ Ethnic groups, additionally, feel deprived and disadvantaged when their political representation is considerable lower than those of other groups in the country. In such cases they tend to blame the state for their status by regarding their deprivation as a constructivist act of political injustice..$^{28}$ Politically discriminated minorities are thus more predisposed to enter into ethnic strife, and this relationship should be represented by a direct positive causality.

26 Tedd R. Gurr, "Why Minorities Rebel: A Global Analysis of Communal Mobilization and Conflict since 1945”, 14(2) International Political Science Review (1993), 161-201, at 162.

27 Ibid. See also Tedd Gurr and Will H. Moore, "Ethnopolitical Rebellion: A Cross-Sectional Analysis of the 1980s with Risk Assessments for the 1990s", 41(4) AJPS (1997), 1079-103.

28 Horowitz, op.cit. note 8; Tedd Gurr, Why Men Rebel (Princeton University Press, Princeton, NJ, 1970). See also Monty Marshall and Tedd R. Gurr, "Peace and Conflict, 2003: A Global Survey of Armed Conflicts, Self-Determination Movements, and Democracy", thesis on file at Center for International Development and Conflict Management, University of Maryland, Baltimore (2003). 


\section{B. Geographical Concentration}

When considering the ethnic security dilemma, Barry Posen stipulates that minorities in ethnically homogenous regions are more advantaged to start ethnic strikes against opposing groups. ${ }^{29}$ The territorial configuration leading to the warfare events between Serbian, Croat and Muslim communities in Bosnia particularly underlines the security dilemma argument.

Steven Grosby further emphasizes that "ethnic groups and nationalities exist because there are traditions of belief and action towards primordial objects such as territorial location." $3^{\circ}$ In such a perspective, it is not surprising that geographical distribution of minority groups is seen as an important explanatory condition when observing ethnic mobilization. In a study using MAR data, Ted Gurr found that geographical concentration had no relevant effect on protest mobilization..$^{\mathrm{I}}$ Monica Toft also conducted extensive research on how the geographical factor impacts violent ethnic mobilization. Her studies reveal the feasibility of this predictor: concentrated or "pocket" minorities are most likely to enter a violent strike while the dispersed, especially urban, minorities are the least predisposed to rebel..$^{32}$ Also, most countries with more than two regionally compact minorities are more likely to be exposed to ethnic rebellion. Further studies, also based on MAR data, validate Toft's findings and confirm the argument that regional dominating minorities have higher tendencies towards violent actions. ${ }^{33}$

Even though the greatest amount of empirical work focuses exclusively on the emergence of interethnic violence, I consider territorial concentration as having an explanatory power for ethnopolitical protest as well. Geographically compressed minorities have better intergroup communication and a stronger shared identity and are therefore easier to mobilize for making their ethnic demands. ${ }^{34} \mathrm{I}$, thus, expect that regionally packed minorities are organizationally better prepared to be actively mobilized at any level of the protest scale.

\section{Intra-Group Fractional Conflict}

Group fractional discrepancies are not an unusual reality in many of the European ethnic communities. Intra-group harmony poses more challenges when it comes to

29 Posen, op.cit. note 11.

30 Grosby, op.cit. note 8, 43.

31 Gurr, op.cit. note 26, 179-180.

32 Toft, op.cit. note 19. See also Monica D. Toft, "The Geography of Ethnic Conflict: Do Settlement Patterns Matter?", paper presented at the Annual Meeting of the Midwest Political Science Association, April 1996, Chicago, IL.

33 Gurr, op.cit. note 3, 75. See also James Fearon and David Laitin, "Weak States, Rough Terrain, and Large-Scale Ethnic Violence since 1945", paper presented at the Annual Meeting of the American Political Science Association, September 1999, Atlanta, GA.

34 Gurr, op.cit. note 3; Gurr, op.cit. note 26; Smith, op.cit. note 15. See also Stephen M. Saideman, "Political Institutions, and Ethnic Conflict: A Pooled, Cross-Sectional Time Series Analysis from 1985-1998”, 35 Comparative Political Studies (2000), 103-129. 
establishing a common and acceptable way to be mobilized. There always will be tendencies to mobilize group members in a certain way in order to maximize the interests of a particular elite section. These "ethnic entrepreneurs" 35 act in a process of internal lure and coercion to increase their fractional interests in a disputed competition with others from within. It could be a long-standing action between fractional coexistence and conflict, continuously marked by communal internal divisions.

The capacity of different intra-group fractions to engage in a common mobilization pattern will depend on a circumstances shaped by the primordial sense of belonging or by a constructivist view for maximizing their chances for political and economic gains. David Lake and Donald Rothchild noted: "In formulating political strategies, ethnic leaders anticipate the consequences of their within-group choices for relations with other groups and, in turn, incorporate the effects of their between-group choices into plans for dealing with their ethnic kin." ${ }^{6}$ The presence of fractional conflict would therefore increase the intra-group dynamics, and thus the mobilization activism might be highly boosted. Hence, active protest would be a realist expectation for an internally divided ethnic minority.

\section{Democracy Level}

The literature constantly underlines the direct influence that democracy has on the intensity to which ethnic conflict is manifest. The direction of causality, however, is still widely disputed among scholars. Many argue that strong democracies are better at handling ethnic strife and, consequently, are less likely to experience violent conflict. The argument is based on the fact that well-established democracies have the necessary instruments to manage pluralism peacefully. ${ }^{37} \mathrm{~A}$ democratic environment may decrease violent conflict, but at the same time, peaceful protest might replace it and flourish. Others think the opposite and argue that democracies provide the tools but also the potential incentives for political actions to manifest. ${ }^{38}$ This scenario might result in a challenging process, which can endanger the democratic system by producing more ethnic conflict. ${ }^{39}$

35 Nelson Kasfir, "Explaining Ethnic Political Participation”, 31 WP (1979), 365-388.

36 David Lake and Donald Rothchild, "Spreading Fear: The Genesis of Transnational Ethnic Conflict”, in David Lake and Donald Rothchild (eds.), International Spread of Ethnic Conflict (Princeton University Press. Princeton, NJ, 1998), at 7.

37 Gurr, op.cit. note 26. See also, Stephen Saideman and William R. Ayres, "Determining the Causes of Irredentism: Logit Analysis of Minority at Risk Data from the 1980s and 1990s." 62(4) JP (2000), 1126-1144; Montserrat Guibernau, Nations without States: Political Communities in the Global Age, (Polity Press, Cambridge, UK, 1999).

38 Horowitz, op.cit. note 8. See also Jack Snyder, When Voting Leads to Violence: Democratisation and Nationalist Conflict (Norton Books, New York, 1999).

39 Alvin Rabushka and Kenneth Shepsle, Politics in Plural Societies: A Theory of Democratic Instability, (Merrill, Columbus, OH, 1972); Bryan Pfaffenberger, "Ethnic Conflict and Youth Insurgency in Sri Lanka: The Social Origins of Tamil Separatism”, in J. Montville (ed.), Conflict and Peacemaking in Multiethnic Societies (Lexington, Lexington, MA, 1991), 
It seems from the literature that the relationship between ethnic mobilization and democratization is more alleged rather than fully demonstrated. More contradictions of how ethnic conflict might evolve can be expected in those countries that face democratic transitions such as former Eastern European communist states. By any means, the supposition is that, with an increase in democratic standards, protest actions are more accommodated and thus more active.

\section{E. Group Ethnic Distinctiveness}

Taking the perennialist and primordialist logics, I believe that different ethnic groups tend to differentiate between each other based on a set of common customs and beliefs. Ethnic communities with distinct ethnic values are inclined to consider themselves as having different ethnic legacies than their neighbouring groups in the country. Under certain conditions, these dissimilarities may well lead to ethnic mobilization in defence of their distinctiveness. Ted Gurr tends to disagree with this logic by mentioning that "the greater a people's dissimilarity from groups with which they interact regularly, the more salient their identity is likely to be." ${ }^{\circ}$ "The literature is further divided over the causal mechanism that links ethnic distinctiveness to ethnic mobilization. Evidences were found that dissimilar ethnic groups disregard the balance of capabilities and have the same mobilization pattern as ethnically strong and distinct communities. ${ }^{4}$ Gurr and Moore, however, found a positive correlation between ethnic distinctiveness and ethnic strife, ${ }^{42}$ whereas Lindstrom and Moore obtained a strong negative impact on militant mobilization and no impact at all on open group mobilization. ${ }^{43}$ I would argue, though, that the decision to protest most likely results from strategic dilemmas. Depending on how much is at stake, it might be assumed that groups with strong ethnic distinctiveness will be more eager to engage in protest actions.

\section{F. Ethnic Fractionalization}

Ethnic diversity is seen in the literature as one of the main predictors for ethnic mobilization. Research suggests that ethnic diversity is the main generator of political insta-

241-258; Stuart Kaufman, "Spiraling to Ethnic War: Elites, Masses, and Moscow in Moldova's Civil War”, 21 IS (1996), 108-138.

40 Gurr, op.cit. note 3, at 67-68.

41 Rupen Cetinyan, "Ethnic Bargaining in the Shadow of Third-Party Intervention", 56(3) IO (2002), 645-677, at 645.

42 Gurr and Moore, op.cit. note 27.

43 Ronny Lindström and Will H. Moore, "Deprived, Rational or Both? 'Why Minorities Rebel' Revisited”, 23 Journal of Political and Military Sociology (1995), 167-190. 
bility and conflict, ${ }^{44}$ yet this causality is negated by some scholar work. ${ }^{45}$ One popular measure of ethnic diversity is a country's ethnic fractionalization score. It reflects the degree to which all ethnic units divide the national population of a particular state.

There are several reasons that explain the need for this explanatory indicator. First of all, ethnic fractionalization is associated with a negative effect on the economic growth, especially in the less democratic countries..$^{46}$ This in turn generates instability, which may lead to ethnic mobilization. Secondly, many scholars argued that plural societies are more exposed to the internal inter-ethnic conflict. ${ }^{47}$ This causality comes from a constant competition between groups, in which each actor demands rights and privileges, which can be seen as a struggle for resources and power. The conflicting actions further sustain ethnic divisions within the state and make inter-communal strife a probable phenomenon. In line with these assumptions, I expected that highly fractionalized societies would be more prone to protest actions.

\section{G. Freedom of Assembly and Association}

In a multiethnic society ethnic minorities rely on a means of association to promote their group interests. John Rawls argues that freedom of assembly and association is a basic liberty of any individual because it represents an extension of liberty of conscience..$^{8}$ It is seen as a human right, by means of coming together and collectively expressing, promoting and defending group interests. ${ }^{49}$ Considering ethnic mobilization, the freedom of assembly and association can be regarded as the right to protest at the group level. Thus, my assumption was that the denial of the right to collectively associate and defend community rights was to come with a certain degree of unrest.

\section{Data, Methodology and Operationalization}

\section{A. Source of Data}

I used data from two sources: MAR and the Quality of Government dataset (QoG). These data sources are widely employed in the scholar work and, thus, provide reliable

44 Horowitz, op.cit. note 8; Gurr, op.cit. note 28; Terry Boswell and William J. Dixon, "Dependency and Rebellion: A Cross National Analysis", 55 American Sociological Review (1990), 540-559; Lee Sigelman and Miles Simpson, "A Cross-National Test of the Linkage Between Economic Inequality and Political Violence", 21 Journal of Conflict Resolution (1977), 105-128.

45 See for instance, James Fearon and David Laitin, "Ethnicity, Insurgency, and Civil War", 97(1) American Political Science Review (2003), 75-90, at 75.

46 Alberto Alesina, Arnaud Devleeschauwer, et al. "Fractionalization", 8 (June) Journal of Economic Growth (2003), 155-194.

47 Rabushka and Shepsle, op.cit. note 39; Horowitz, op.cit. note 8.

48 John Rawls, Political Liberalism (expanded ed.; Columbia Classics in Philosophy; Columbia University Press, New York, 2005).

49 Jeremy McBride, Foredoom of Association, The Essentials of Human Rights (Hodder Arnold, London, 2005), at 18-20. 
indicators for my descriptive and empirical models. Their characteristics are summarized as follow:

MAR data is the most comprehensive set in the field that targets the most discriminated minority groups..$^{50}$ The sampled population in MAR is composed of those communal ethnicities that are hurt by discriminatory treatment ${ }^{5 \mathrm{I}}$ compared with other groups in the state. Group discrimination is regarded as the base for political mobilization for the promotion of their communal interests. This data records the minority "at risk" status in contrast with the majority group(s). Only those ethnic minorities are included in the dataset that have a more-inferior collective status than the relative condition of others in the country. An ethnopolitical group is considered "at risk" when it fulfils one of the following two criteria: ${ }^{2}$

1. The group "collectively suffers, or benefits from, systematic discriminatory treatment vis-à-vis other groups in a society"

2. "Collectively mobilizes in defence or promotion of its self-defined interests"

Additionally, for each minority case that is included in the MAR data, two more operational guidelines are established. Endangered communal groups are counted only in those countries in which the population exceeds 500,000. Furthermore, the group itself should count at least 100,000 members or represent at least $1 \%$ of the total population of the country. To minimize the danger of the subjective mobilization bias, I excluded some initial groups from the dataset. I focused only on those "at risk" groups that have a longstanding historical presence in a specific country's location. Thus, the recent migrant ethnic groups are not listed in my sample even though they comply with the criterion of "at risk" established by the MAR project. Examples of groups that were excluded from the analysis are foreign workers in Switzerland, British AfroCaribbean, British Asians, Muslims (noncitizens) in France, etc. Finally, I came up with 55 disadvantaged ethnic minorities in 24 European countries..$^{53}$

50 MAR data was computed by consulting various sources, including human rights reports, governmental and expert opinion, journalistic accounts, reports from the international organizations, etc. A substantial effort was made to control the coding bias and to minimize the subjective bias resulting from using many qualitative sources. For more information see <http://www.cidcm.umd.edu/inscr/mar >.

51 There are a series of critiques based on the selection of minorities "at risk". One limitation is that the MAR dataset only included groups that are discriminated against, i.e., groups with a high tendency to be dissatisfied with their political status. Put another way, it excluded other politically active groups that were currently not considered at risk-e.g., for Switzerland, the only groups listed are Jurassians (Swiss citizens living in the Canton of Jura) and foreign workers. On the other hand, the Romansh-speaking minority, or for that matter the entire Italian- and French-speaking populations (outside of Jura), who are also in the minority were not listed. The same sampling problem arises in the case of Walloon and Flemish communities in Belgium, Galicians in Spain or Sami minority in Scandinavia.

52 "Minority at Risk IV Dataset: Users Manual 030703", version 2003, 117, at 5, at <http:// www.cidcm.umd.edu/mar/data.asp $>$.

53 Please refer to Table 4 in the Appendix, which shows the sampled "at risk" groups employed in the analysis, by country. 
The QoG data ${ }^{54}$ was the second empirical base for my analysis. It is a compilation of different types of smaller datasets and was built on the basis of expert-coded indicators, aggregated individual-level survey data, international organizations' expert data or different demographic, social and political measures. In general, QoG aims at performing research on the causes, impact, quality and nature of political governance. The indicators provided for my analysis were coded at the country level and provide reliable information close to the cases under analysis.

Finally, the timeframe of this analysis was set to capture the mobilization pattern experienced by European minorities after the termination of the cold war era. My sampled time, therefore, comprises the period between 1991 and 2003.

\section{B. Operationalization}

All variables included in the analysis are judgmental ordinal, dichotomous or composite variables. Some of them were re-coded to better fit the argument of this study. In total, there are eight explanatory indicators to be employed in testing the emergence of protest mobilization. Their operationalization is detailed below.

Ethnopolitical protest: the dependent variable, ethnopolitical protest, is defined from the initial "Prot" indicator of the MAR dataset. To better include the protest indicator in the ordinal model, I further established four hierarchical values: no protest, low-intensity protest, medium-intensity protest and high-intensity protest. In this order, protest actions range from no protest, to verbal and symbolic actions, and up towards mass demonstration and riots. For a complete visualization of this hierarchy scale but also for all protest activities assigned to each value, see Table 3 in the Appendix.

Former ideological regime: I included a dummy that cluster ethnic minorities into three distinct regional groups: Balkans, Former Soviet Eastern Europe, and Western European democracies. The reason behind the choice to split them is the former ideological environment in which "at risk" minorities originate their mobilization patterns.

Political discrimination: this is a dichotomous variable recording whether or not the group is politically discriminated. It builds on the former "poldis" indicator in the MAR dataset. The contained information registers the discrimination practices that vary from formal political inequities to restrictive and social exclusion actions. The range of political discrimination is, however, beyond the aim of this study. I am not directly interested in whether an ethnic group suffers from neglecting policies or from social exclusion mistreatments. The simple presence of any form of political intolerance confirms the discriminatory status of an ethnic minority, and thus it was coded as 1 (the presence of political discrimination).

54 This is a database coded by researchers at the Quality of Government Institute, Goteborg University. For more information regarding this dataset see Jan Teorell, Sören Holmberg and Bo Rothstein, "The Quality of Government Dataset”, The Quality of Government Institute, University of Gothenburg, version 15, May 2008, at <http://www.qog.pol. gu.se>. 
Geographical concentration: this indicator measures to what extent an ethnic group forms a compact regional community or, the opposite, is dispersed across the country. It originates from the "groupcon" variable in the MAR dataset. Dispersed groups (coded here as 0 ) are widely scattered or primarily urban minorities. Compact groups (coded here as 1) are solid concentrated minorities that make up the majority population in a certain region within the state.

Intra-group tensions: this dichotomous indicator underlines the presence of factional conflict (coded as 1) inside the group. It was derived from the "intracon" indicator from the MAR data.

Level of democracy: the information measuring the annual democracy scores came from the combined Freedom House/Imputed Polity measure 55 of democratic performance, calculated in terms of civil liberties and political rights. According to Hadenius and Teorell,,$^{56}$ this index outperforms all rival indices of democracy in both reliability and validity. This index ranks the level of democracy on a scale from 0 to 10. A score of 10 indicates strong democracies, whereas a score of 0 indicates strong autocracies. The variable listed in the model considered countries scoring over 7.5 to be established democracies and countries with values below 4 to be non-democracies. The values in between were assigned to semi-democratic regimes.

Ethnic fractionalization: the indicator used in my analysis was Fearon's index of ethnic fractionalization constructed from the CIA World Factbook combined with a measure of linguistic fractionalization. Employed from QoG data, it records the probability that two randomly selected individuals from a country will belong to different ethnic groups ${ }^{57}$ Values range within the interval of 0 , a perfectly homogenized society, and 1, a highly fragmented community.

Group ethnic distinctiveness: I measured ethnic group distinctiveness through the "Ethdif $x x$ " index employed in MAR. It cumulates values related to language, customs, believes and race..$^{8} \mathrm{I}$ was interested in observing mobilization patterns among groups having strong cohesion relative to those with weak ethnic distinctiveness. The initial MAR indicator has values scaling from 0 (no cohesion) to 11 (very high cohesion). Establishing 5 as the breaking point, the sample was thus divided into groups having stronger ethnic distinctiveness and communities with weak such values.

Freedom of assembly and association: initially it was constructed in the Cingranelli-Richards (CIRI) Human Rights Dataset and later cointegrated in the QoG dataset. I used the "ciri_assn" indicator measuring the standards of freedom of

55 For more information on the Freedom House/Imputed Polity data see <http://www. freedomhouse.org>.

56 Axel Hadenius and Jan Teorell, "Cultural and Economic Prerequisites of Democracy: Reassessing Recent Evidence” 39 Studies in Comparative International Development (2005), 87-106.

57 James D. Fearon, "Ethnic and Cultural Diversity by Country", 8 Journal of Economic Growth (2003), 195-222, at 208.

58 For a critique of this index, see James Fearon and David Laitin, "Collaborative Project: The Minorities at Risk Database and Explaining Ethnic Violence", NSF Grant SBR9876477, 4/99-3/00. Unpublished paper. Available at <http:/www.stanford.edu/group/ ethnic/DLJFNSF.doc>. 
assembly and association at the country level. The indicator employed in my model had three values: 1 , freedoms that are severely restricted or denied completely; 2 , freedoms that are limited for all citizens or severely restricted for some groups; and 3, freedoms unrestricted for all citizens.

\section{Empirical Model}

A typical estimation technique for the ordinal dependent variables is through discrete choice modelling via either ordered probit or logit. I chose this methodology for this study to better reflect the strength and limitations of the data. Discrete choice modelling provided me with the ability to explain variations in ethnic mobilization at each level of the protest intensity. This approach avoids treating the differences between protest levels as uniform, as it is in the case of a least-squares regression. The equation below estimates my raw model by pooling data.

$$
\text { (1) } \quad \text { Pit }=\beta 1 \text { kit }+\beta 2 \text { xit }+ \text { eit } \quad(i=1, \ldots N ; t=2, \ldots T) \text {, }
$$

where Pit is the dependent variable that records, for every year, the protest status of ethnic groups by means of an ordinal scale coded as 0 (for no protest), 1 (for lowintensity protest), 2 (for medium-intensity protest), and 3 (for high-intensity protest); kit stands for those explanatory variables related to protest at the group-level i at time $\mathrm{t}$; xit relates to several control variables at the country level, ethnic fractionalization, democracy level, freedom of association, which are assigned to the characteristics of the group $i$ at time t; eit is equal to time and group specific error that is presumed to be normally distributed and uncorrelated with the control variables.

In my specification, to circumvent the issues that arise because of the use of pooled data, I accounted for individual heterogeneity and inter-temporal dependency. First, I controlled for the group fixed effects by considering a procedure to "de-mean" the data as it was proposed by Yair Mundlack in 1978.59 This technique controlled for the fixed effects in the model by considering the within-group means of the regressors. Second, I integrated in the final model the constructed lagged variables that count for the status of protest at $t-1$. The lagged variables of the dependent indicator, used as explanatory variables, are assumed to be independent of the error term as in the form of a "true state dependence". ${ }^{60}$ This might be a strong assumption and I acknowledge it as a possible limitation of the analysis.

Thus, we obtain:

(2) Pit $=\beta 1$ kit $+\beta 2$ xit $+\alpha i+\varepsilon i t \quad(i=1, . . N ; t=2, \ldots \mathrm{Ti})$ and

(3) Pit $=\beta 1$ kit $+\beta 2$ xit $+\beta 3$ Pit $-1+\alpha \mathrm{i}+\varepsilon$ it $\quad(i=1, . . \mathrm{N} ; \mathrm{t}=2, \ldots \mathrm{Ti})$,

59 Yair Mundlak, "On the Pooling of Time Series and Cross-Section Data", 46(1) Econometrica (1978), 69-85.

60 Bo E. Honoré and Ekaterini Kyriazidou, "Panel Data Discrete Choice Model with Lagged Dependent Variables”, 68(4) Econometrica (2000), 839-874. 
where Pit-1 is the observed group's previous-year protest condition, which accounted for the time dependency in the sample; $\alpha \mathrm{i}$ is a group-specific and time-invariant component that controlled for the systematic fixed effects associated with the data; zit is again the time- and group-specific error terms, which are considered to be exogenous, normally distributed, independent and uncorrelated across groups, years and with the Mundlack's terms.

The ordered discrete choice model indicates only the general tendency of the coefficients applied to the hierarchical order of the dependent variable. To capture the true effects in the ordinal scaling, my model estimated the marginal effects of all variables employed in this study. My analysis was conducted in STATA, and thus, it calculated the marginal effects at the means of the independent variables by using the prediction associated with the previous ordinal probit estimation command. By calculating the marginal effects, I saw how per-unit change in the independent indicators affected the relative intensity of the ethnopolitical protest. Since, according to William Greene, ${ }^{6 \mathrm{r}}$ the interpretation of the coefficients of an ordered probit is quite unclear in the literature, I also interpreted the results in terms of the marginal effects.

\section{Data Analysis: Patterns and Trends}

\section{A. The Descriptive Path}

Ethnic protest is one form of conflict for which many ethnic minorities go for in externalizing their dissatisfaction in relation to the dominant authority. The intensity of protest, however, might vary across time as the conflicting demands are tackled among the actors involved. Figure 1 shows the overall trends in protest intensity over the observed 13 years. In general, the cumulative pattern of protest has a descendent slope. This means that the active ethnic strife declined within the 1991 and 2003 time span. It can be observed that there was a significant decreasing dip in ethnopolitical activism at the end of the 1990s, more exactly between 1997 and 1999. A significant recovery followed just after that. The most affected patterns were across the mediumand high-level protest activities (sabotages, mass demonstrations and riots).

Less protest mobilization during that period followed some major conflict settlements all around Europe. There was increasing support, after 1995, for solving the interethnic conflict in Azerbaijan (Nagorno-Karabakh) and Georgia (in Adzharia, Ossetia and Abkhazia). The civil war in Bosnia ended in 1995 with the Dayton agreements, and in 1998, the Northern Irish republicans and the unionists agreed to a national compromise via the Good Friday accord. Shortly afterwards, in 1999, the IRA agreed for an unlimited suspension of its terrorist activity. At the same time, in 1997 many Central and East European countries received invitations to join NATO. In parallel, there were signs for a clear EU membership for all these countries. This chain of events has created a more stable political environment and a period of a euphoric lull among disadvantaged minorities with weak possible motivations for high protesting actions.

61 William H. Greene, Econometric Analysis (Prentice-Hall, Englewood Cliffs, NJ, 2000), 876. 
Figure 1

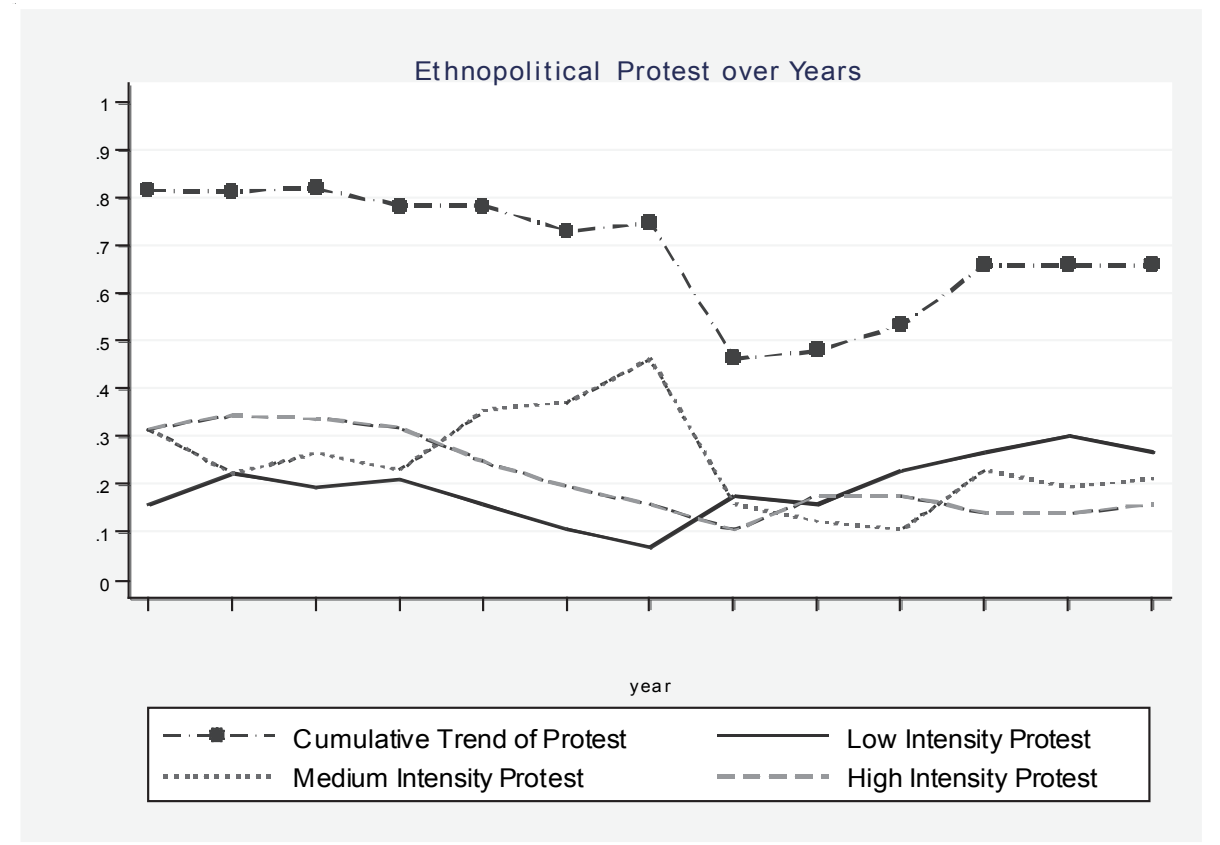

Apart from this opportunistic chain of events, it might be that protest preferences of ethnic groups shifted towards other levels of protest. There was indeed a consistently increasing path in low-intensity protest activities (public letters, petitions, posters, publications, agitation etc.), with values reaching almost two times higher in 2002 to 2003 than at the beginning of 1990s. At the same time, higher levels of protest steadily decreased in post-1990 Europe. Even though high and medium means of protest have weakened over time, they still have a persistent share in protest preferences among ethnic minorities (because almost $20 \%$ are still employed in mass protest in 2003). For a better understanding of this phenomenon, we might look into the dynamics of different mobilization levels and see how the protest transitions rates perform over time.

\section{B. Protest Dynamics}

Dynamics of ethnic mobilization show the degree to which groups choose to change their active mobilization status across a certain period of time. In accord with previous findings, there are also a number of interesting substantive results that can be seen in Table 1. At a first sight, the data show that $83 \%$ of inactive minorities (non-protesting) in 1991 remained in the same non-mobilization status up until 2003. It represents a remarkably stability in the passive protest mobilization over years. It also implies that many "at risk" minorities might lack clear incentives to highly mobilize and protest. This is supported by the fact that those groups that left the "non-protesting" status moved mainly into the low protest category. In fact, this particular protest intensity 
also had a steady trend across years. Around 65\% of groups remained in low protest activities across the observed time period. This is, however, less surprising because the evidence presented in Figure 1 supports the stability and the increasing trend of the low-scale protest activities.

Table 1. Transition Rates of the Ethnopolitical Protest from 1991 to 2005

\begin{tabular}{|c|c|c|c|c|}
\hline \multirow[b]{2}{*}{ Ethnopolitical Protest } & \multicolumn{2}{|l|}{$1991, \%$} & \multicolumn{2}{|l|}{$2003, \%$} \\
\hline & No protest & Low intensity & $\begin{array}{l}\text { Medium } \\
\text { Intensity }\end{array}$ & High Intensity \\
\hline No protest & 83.25 & 9.85 & 1.97 & 4.93 \\
\hline Low Intensity & 10.48 & 64.52 & 15.32 & 9.68 \\
\hline Medium Intensity & 9.70 & 9.09 & 58.79 & 22.42 \\
\hline High Intensity & 6.29 & 9.79 & 29.37 & 54.55 \\
\hline
\end{tabular}

At the same time, the mobilization status of highly and moderately mobilized minorities did not changed radically. Almost 55\% of highly mobilized groups, and 59\% of medium intensity protesters were in the same protest category in 2003 as they were initially in 1991. As a matter of fact, most of the ethnic groups who changed their protesting level went mostly in the proximity of their initial mobilization status. Almost one third of those groups engaged in high-intensity protest in 1991 decreased their mobilization pattern to the medium protest category instead of moving towards low intensity or no mobilization in 2003. In the same line, $22 \%$ of medium-level protesters moved towards the higher level of protest instead of going lower in their mobilization pattern.

Generally, we may conclude that the higher the initial protesting status, the greater probability that an ethnic group will decrease its protest actions across years. The decline in protest, however, is not a total change in protest intensity, because groups tend to choose similar actions of protest close to their initial protesting status. Accordingly, the dynamic scale of protest is not represented by extreme transitions, which is somehow surprisingly given the important political changes and ideological transition of the decade analyzed. I believe that the utmost protest transitions require a substantial organizing effort that might be hard to achieve in such a relatively short period of time.

\section{Empirical Findings-Marginal Effects}

This section presents the empirical findings of the ordered probit models, calculated in terms of marginal effects. Table 2 presents the results from equation 1, which assesses the protest intensity without exploiting the unobserved heterogeneity and longitudinal characteristics of the data. Within this model, almost all indicators appear to have a statistically significant effect on protest mobilization. Marginal effects indicate that ethnic minorities residing in Western European democracies have higher probability of engaging in low-intensity protest and have less keenness for mass protest. The effects for political discrimination have positive and significant signs as the protest 
increases at the highest level. As expected, this form of discrimination displays high response in terms of high protest actions and less involvement in symbolic protest (public letters, petitions, posters, publications, agitation, etc.). The probability that disadvantaged minorities choose mass demonstration and riots increased by 15 percentage points when political discrimination was present. These estimates suggest that the status of political discrimination comes with a higher desire for higher protest.

There is also a strong positive relationship between the minorities' territorial concentration and the outburst of high-intensity protest. Groups that are territorially concentrated are more likely to mobilize more intensely. As previously demonstrated, concentrated groups have higher community feelings and, consequently, have stronger incentives to take part in large protest actions. On the other hand, the consistency of the geographical factor had a significantly negative impact on the likelihood that an ethnic group would take part in low-intensity protest. We can logically conclude that ethnically dispersed minorities might be more comfortable engaging in symbolic forms of protest to disseminate their ethnic demands than would regionally compact groups. 
The Conflicting Path of Ethnic Diversity: Protesting Minorities in Europe

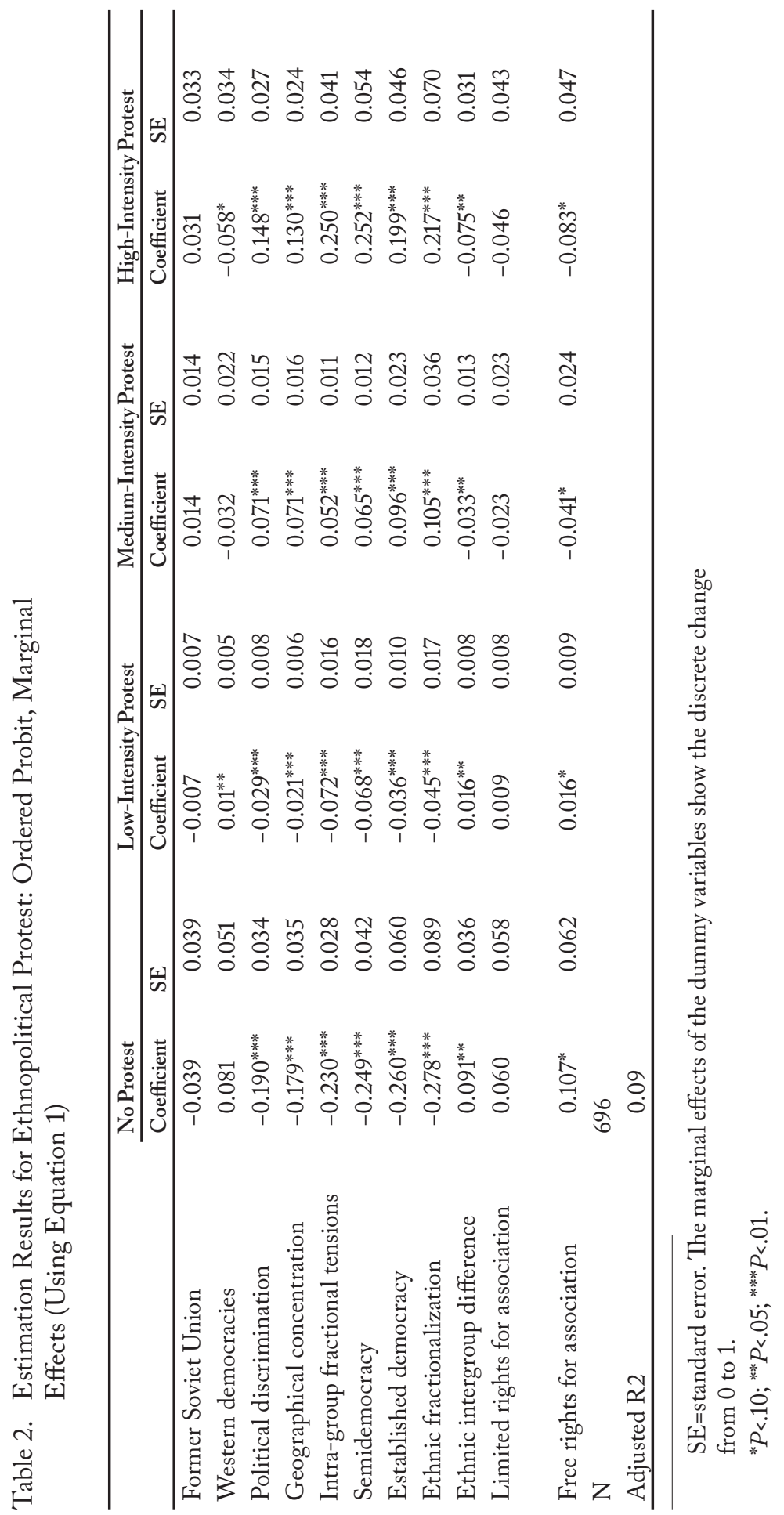




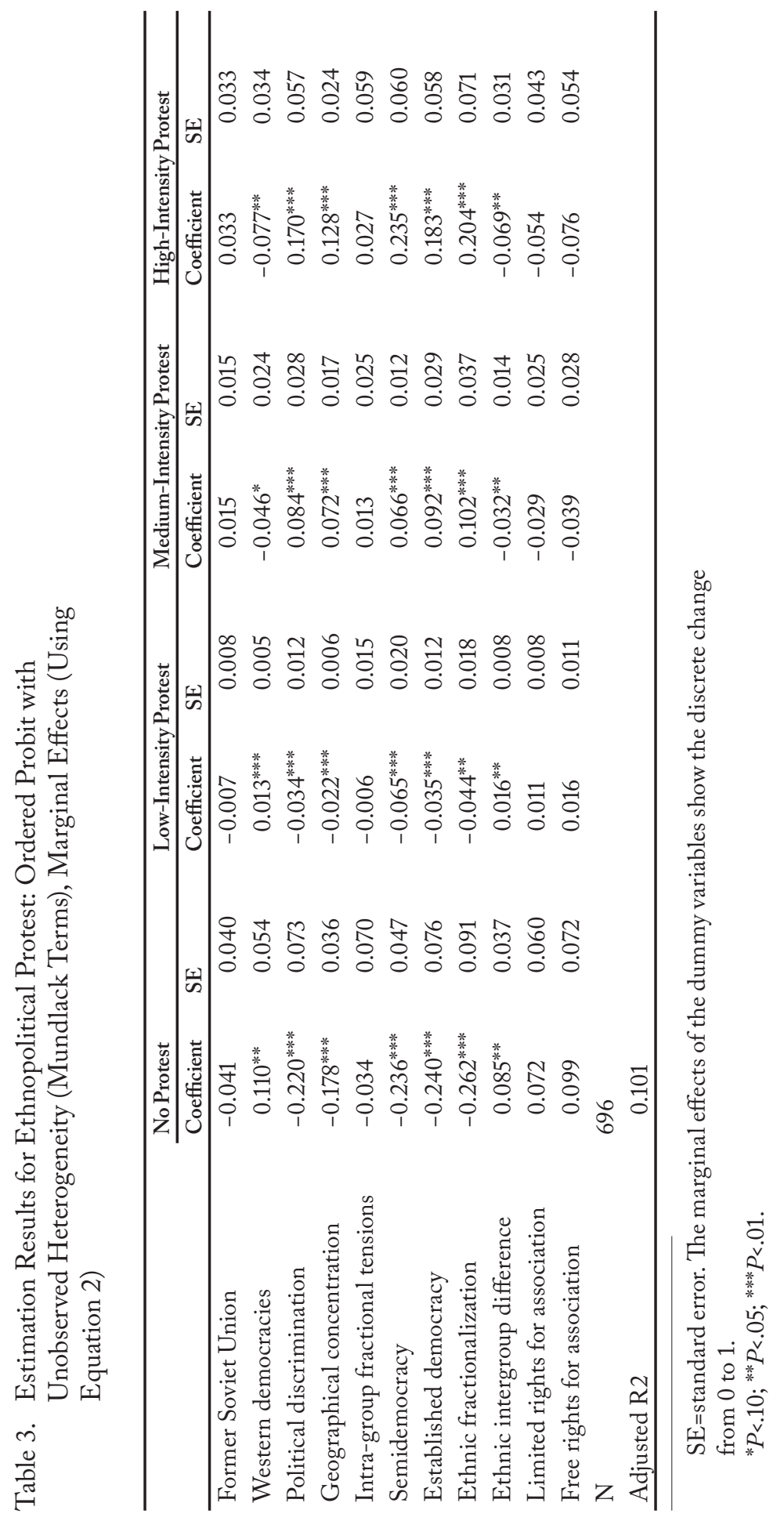


Further on in the ordered probit analysis, I found that the effect of the intra-group factional tensions had a significant, positive and strong impact on the occurrence of largescale demonstrations. Yet, the same indicator has a negative impact on the lowest level of protest. Divided groups are thus more prone to mobilize for higher forms of protest and not less. The reason behind this choice might be that strong protest actions are seen by group conflicting elites as the proper way of achieving the proposed factional outcomes.

Controlling for democracy level, the effects show that both countries in transition and established democracies have a higher probability of protesting at the higher levels. Moreover, in these political environments, disadvantaged minorities appear to prefer medium and mass protest to softer strife activities. According to Horowitz, ${ }^{62}$ many ethnic groups try to explore the transition institutional chaos into their own benefit, also by engaging in mass mobilization. In advanced democracies, large-scale protest might be also the only acceptable way for many ethnic minorities to achieve their desired group goals.

Marginal coefficients, measuring the effect of ethnic fractionalization on minorities' strife are positive and statistically significant for higher levels of protest. The estimates thus support the supposition that disadvantaged minorities in ethnically fractionalized societies are more prone to participate in mass protest. There was also a significant negative effect of strong ethnic distinctiveness on high levels of protest mobilization. These results were contrary to my expectation but in line with Ted Gurr's ${ }^{63}$ previous finding that protest is less intense among groups that are more distinct from the majority population in the country. As far as general rights for association were concerned, I found that the direction of causality was in line with my posted assumption. The effects highlight that the probability of engaging in high-level protest decrease in a country that allows for free civic liberties.

However, the above-described results were obtained without using the temporal characteristics of my dataset. Thus, they do not take the unobserved heterogeneity and time dependency into account, which implies that the coefficients obtained from equation 1 may be ambiguous. To see whether or not the described results were due to the influence of the unobserved heterogeneity or time dependency, I further employed two additional models specified in equations 2 and 3 .

Table 3 presents the marginal effects of the model specified in equation 2. This model controlled for the systematic fixed effects associated with my data. After taking the unobserved heterogeneity into account, most of the determinants of ethnopolitical protest estimated by equation $1 \mathrm{kept}$ their significance but also their previous direction of causality. Once fixed effects were considered, only the intergroup fractional tensions and freedom for assembly and association did not significantly influence the intensity of protest mobilization.

Table 4 further presents the marginal effects for each level of protest by considering both unobserved heterogeneity and time dependence in the data. After controlling for these factors, I found that some of the important determinants of protest that had been previously estimated in equation 1 lost their significance. This model underlines

62 Horowitz (2000), op.cit. note 8 .

63 Gurr, op.cit. note 3, at 67-68. 
the importance of taking both the systematic unobserved effects and time dependency into account. From all indicators employed, political discrimination, geographical concentration, democracy level, and ethnic fractionalization kept their previous direction of causality at a significant level.

Further on, I found that time dependency was a very important and significant determinant of the current protest status. The results indicate that those ethnic groups that were previously at the "no protest" level were $67 \%$ more likely still be in the same passive protest level at the moment. This prediction again reinforces the idea that the latent version of protest tends to persist across time. At the same time, minorities that at $t-1$ were involved in mass demonstrations had a significant negative probability of being in no protest in $t$. 
The Conflicting Path of Ethnic Diversity: Protesting Minorities in Europe

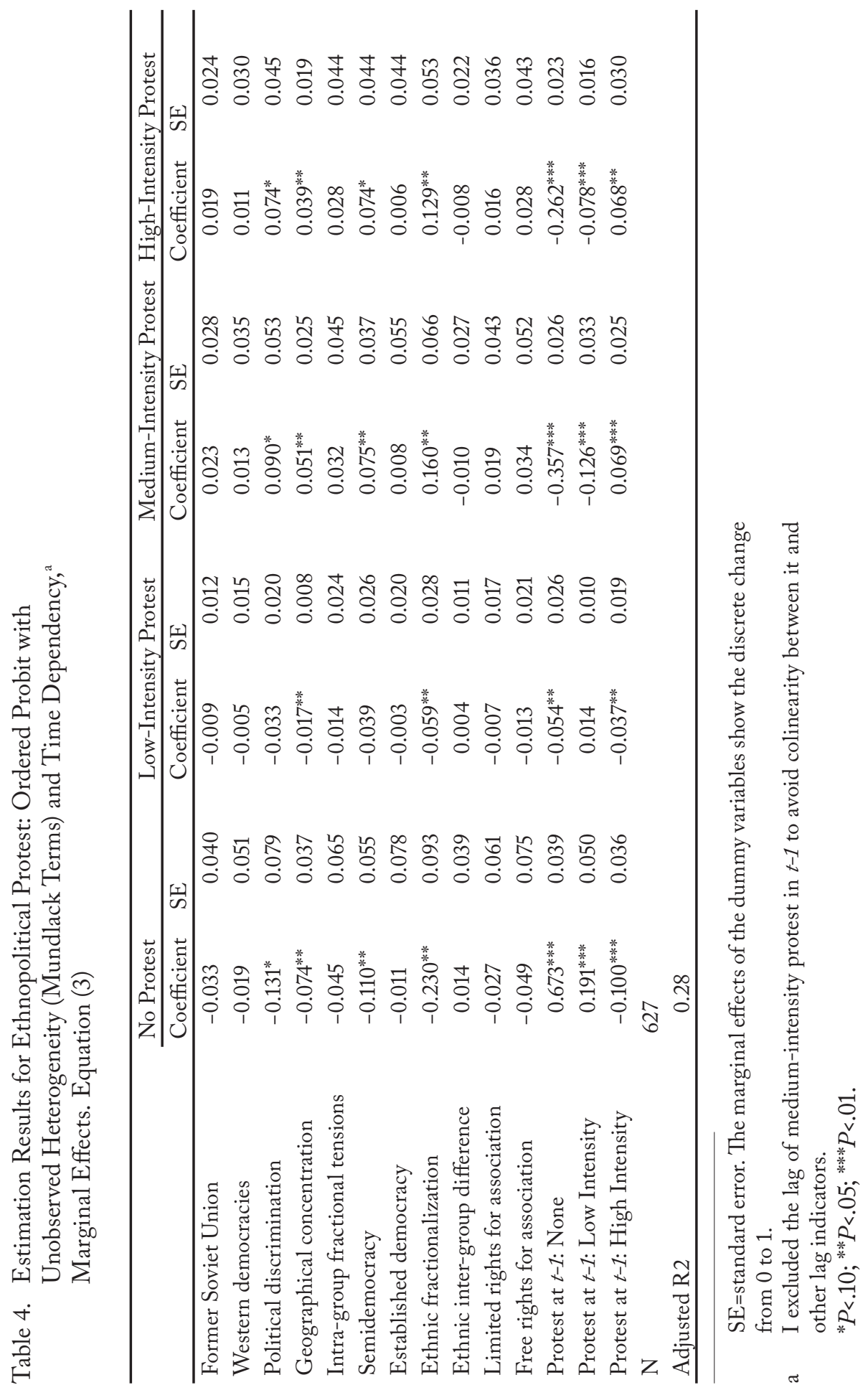


We previously saw that low-intensity protest had an increasing trend over all of the observed period. The longitudinal evidence shows that those minority groups that in $t-$ 1 had been employed in mass demonstration or no protest had a negative probability of being currently found in the low-intensity protest category. As a matter of fact, if these results are correlated with the ones from the no-protest category but also from higher protest levels it can be concluded that the lowest form of protest is a rigid but also a transitory stage toward no protest. Those groups that were previously engaging in low protest activities had a 19 percentage points higher probability of stopping protesting in $t$ and at the same time were less likely to move toward higher forms of protest. The observed rigidity resulted from the fact that irrespective of any previous mobilization status, there was a negative impact on the current low level of protest. This inflexibility but also the downstream transitory status of the lowest form of protest might explain its increasing trend over time as seen in Figure 1.

Both medium and high levels of protest show an appreciable stability of their current protest level in relation to their previous intensity status. Groups engaged in mass protest at $\mathrm{t}-1$ had a higher probability of keeping the same status in $t$ or decreasing their mobilization status to medium-intensity protest. Similarly, I found that if the previous protest status was of medium intensity, the current likelihood of being in mass protest increased by $6.8 \%$. On the other hand, if the previous protest intensity was of no protest or of low-intensity protest, the probability of the current status being in high protest decreased by $26 \%$ and $7.8 \%$, respectively. In line with the findings shown in Table 1 , this implies that a change in protest intensity over time happens more progressively and less radically.

\section{Conclusions}

Claims about the way ethno-political challenges evolve are linked by filaments of assumptions that go back to the basic nature of conflict. In the context of this study, ethnopolitical protest was viewed as an effective tool in promoting ethnic demands and at the same time keeping inter-ethnic tensions at a relatively peaceful level. I tried, therefore, to underline certain patterns and trends governing the ethnopolitical protest since the end of the cold war in Europe. The central findings of this paper confirm the expectations gathered previous scholarly work: that the general trend in ethnic protest is a decreasing one. An important particularity, however, should be mentioned. Although the most-intense protest activities decreased, the low-level protest increased markedly across Europe. Empirical evidence also shows that this type of protest tends to have a slightly different explanatory pattern than do all other forms of protest. Given the growing preferences for this type of resistance among European disadvantaged minorities, further research is recommended to explore the consistency of this particular protest intensity.

When employing the protest dynamics, I found that those ethnic groups that originally stayed lowly mobilized were more prone to keep this initial condition over time. At the same time, a considerable proportion of highly mobilized groups did stay in the same protesting status over the years. Only less than half of the highly mobilized minorities chose to decrease their protest intensity to lower levels during the analyzed 13 years. Transitions, however, were mainly to the neighbouring levels of protest, and 
limited evidence could be found of extreme transitions. For this reason, the strength of protest mobilization must be approached as a long-term consistent phenomenon.

According to the statistical analysis, politically discriminated minorities protest at the highest levels. When taking the regional factor into account, "at risk" ethnicities in Western democracies engage less in mass protest than do groups in former communist countries. In line with my expectations, geographical concentration and intragroup frictions seems to be strong significant factors in predicting the appearance of ethnic protest. In the same context, both transition states and strong democracies successfully accommodate high protesting actions. Alike, ethnic mobilization is more active in ethnically divided societies. Against my initial assumptions, minorities with strong feelings of their ethnic distinctiveness engaged more in low-intensity protest and less in mass demonstrations. By considering the rights for association, I found that their presence provides ethnic minorities with fewer incentives to engage in high-level protest.

This study also demonstrated the importance of considering the unobserved heterogeneity and time dependency that have not been explored as much in previous research on ethnic mobilization. I first estimated a fixed-effects model (equation 2), without employing the temporal characteristics of the data used. The results did not change radically nor did their significance or direction of causality. However, once both the unobserved heterogeneity and time dependency were considered (equation 3), only the political discrimination, geographical concentration, democracy level and ethnic fractionalization were significantly associated with protest mobilization.

Controlling for the protesting status at $t-1$, I found that the intensity of protest from the previous year had a significant influence on minorities' current protest intensity. This influence, however, widely differed across different levels of protest. The current no protest status was highly and positively influenced by the prior no and lowintensity protest. On the contrary, current low-intensity status was negatively affected by any previous form of protest. On its extreme side, high-intensity protest was only positively affected by previous medium-level mobilization and negatively by other protest statuses. As in the case of the transition rates presented in Table 1, I conclude that the probability of radical changes in protest status over time is very slim. These results suggest that time dependency, either positively or negatively affecting protest intensity, will keep the same slowly moving pattern in the coming future.

This study indicates that the empirical analysis of peaceful mobilization can provide fruitful yet challenging results. Therefore, further efforts should be made in improving this research. Apart from some recommendations made in the text, more scholarly work is suggested to further attest the dynamic trend of ethnic protest. One recommendation is to generate quality empirical work on the impact of causal conditions on the probability to enter or exit protest mobilization. Last but not least, an empirical correlation should be made in longitudinally attesting both the peaceful (protest) and violent (rebellion) mobilization trends among at-risk minorities. In doing so, an effort should be made to finding data-poof solutions and incorporate in the analysis a wider range of ethnic groups, including the majority populations. This attempt will generate more-consistent comparative findings around the concepts of ethnicity and ethnic mobilization. 


\section{Appendix}

Table 3. The dependent variable: Ethnopolitical protest

\begin{tabular}{|c|c|c|}
\hline $\begin{array}{l}\text { Coded } \\
\text { Values }\end{array}$ & Labels in the original MAR variable (PROT) & $\begin{array}{l}\text { Recoded Protest Variable } \\
\text { Employed in the Analysis }\end{array}$ \\
\hline 0 & No protest $r$ & No protest \\
\hline 1 & $\begin{array}{l}\text { Verbal Opposition } \\
\text { (Public letters, petitions, posters, } \\
\text { publications, agitation, etc.) }\end{array}$ & Low-intensity protest \\
\hline 2 & $\begin{array}{l}\text { Symbolic Resistance } \\
\text { Scattered acts of symbolic resistance } \\
\text { (e.g., sit-ins, blockage of traffic, sabotage, } \\
\text { symbolic destruction of property) }\end{array}$ & Medium-intensity protest \\
\hline 3 & $\begin{array}{l}\text { Small Demonstrations } \\
\text { (Demonstrations, rallies, strikes, } \\
\text { and/or riots with }<10,000 \text { people) }\end{array}$ & High -intensity protest \\
\hline 4 & $\begin{array}{l}\text { Medium Demonstrations } \\
\text { (Demonstrations, rallies, strikes, } \\
\text { and/or riots with } 10,001-100,000 \text { people) }\end{array}$ & \\
\hline 5 & $\begin{array}{l}\text { Large Demonstrations } \\
\text { (Mass demonstrations, rallies, strikes, } \\
\text { and/or riots with }>100,000 \text { people) }\end{array}$ & \\
\hline
\end{tabular}

Table 4. Ethnic groups by country

\begin{tabular}{l|l}
\hline Country & Ethnic Group \\
\hline Albania & Greeks \\
\hline Azerbaijan & Armenians \\
\cline { 2 - 2 } & Lezgins \\
\cline { 2 - 2 } & Russians \\
\hline \multirow{2}{*}{ Belarus } & Poles \\
\cline { 2 - 2 } & Russians \\
\hline \multirow{2}{*}{ Bosnia } & Croats \\
\cline { 2 - 2 } & Muslims \\
\cline { 2 - 2 } & Serbs \\
\hline \multirow{2}{*}{ Bulgaria } & Turks \\
\cline { 2 - 2 } & Rroma \\
\hline Croatia & Serbs \\
\cline { 2 - 2 } & Rroma \\
\hline Czech Republic & Slovaks \\
\cline { 2 - 2 } & Rroma \\
\hline
\end{tabular}




\begin{tabular}{|c|c|}
\hline Estonia & Russians \\
\hline \multirow[t]{3}{*}{ France } & Basques \\
\hline & Corsicans \\
\hline & Rroma \\
\hline \multirow[t]{2}{*}{ Greece } & Muslims/Turks \\
\hline & Rroma \\
\hline \multirow[t]{4}{*}{ Georgia } & Abkhazians \\
\hline & Adzhars \\
\hline & Ossetians (South) \\
\hline & Russians \\
\hline Hungary & Rroma \\
\hline \multirow[t]{3}{*}{ Italy } & Sardinians \\
\hline & South Tyrolean \\
\hline & Rroma \\
\hline Latvia & Russians \\
\hline \multirow{2}{*}{ Lithuania } & Poles \\
\hline & Russians \\
\hline \multirow[t]{3}{*}{ Macedonia } & Albanians \\
\hline & Serbs \\
\hline & Rroma \\
\hline \multirow[t]{2}{*}{ Moldova } & Gagauz \\
\hline & Slavs \\
\hline \multirow[t]{2}{*}{ Romania } & Magyars (Hungarians) \\
\hline & Rroma \\
\hline \multirow[t]{2}{*}{ Slovakia } & Hungarians \\
\hline & Rroma \\
\hline \multirow[t]{3}{*}{ Spain } & Basques \\
\hline & Catalans \\
\hline & Rroma \\
\hline Switzerland & Jurassians \\
\hline \multirow[t]{2}{*}{ United Kingdom } & Catholics in Northern Ireland \\
\hline & Scots \\
\hline \multirow[t]{3}{*}{ Ukraine } & Crimean Russians \\
\hline & Crimean Tatars \\
\hline & Russians \\
\hline \multirow[t]{5}{*}{ Yugoslavia } & Croats \\
\hline & Hungarians \\
\hline & Kosovo Albanians \\
\hline & Sandzak Muslims \\
\hline & Rroma \\
\hline
\end{tabular}

